\title{
Research on Digital Resource Evaluation Index System of University Libraries Faced with Purchasing Decision
}

\author{
Shi Ruoyao \\ Jianghan University Library \\ Jianghan University \\ Wuhan, China \\ 191197593@qq.com
}

\begin{abstract}
From the point of purchasing decision needs of digital resources construction of university library, this paper proposes the secondary level index weight system, which evaluates the four aspects of digital resource content, organization level, user guarantee and utilization performance, and puts forward the detailed scoring rules.
\end{abstract}

Keywords_purchasing decision; university library; digital resource evaluation; index system

\section{INTRODUCTION}

With the evolution of the whole academic environment in universities, comprehensive, diversified and digital collection structure adjustment is a new direction of library resource construction. Proportion of digital resources will further increase [1]. Purchasing of commercial academic resources from database trader with single database as unit is the most important approach of construction of collected digital resources of university libraries. Significance of evaluation on collected digital resources with scientific, systematic and reasonable evaluation index system lies in optimization of collection structure, support of purchasing decision, improvement of resource utilization performance, guidance of library service and other aspects.

\section{Evaluation ObJect, Content and Principle}

Take Jianghan University library as an example, in 2016, the library totally purchased 46 digital resources, including 42 databases, 156 sub-databases and 4 kinds of software. The resource types involve electronic books, full text of periodicals, indexes, streaming medias, picture libraries, thematic databases, subject navigations, discovery systems, autonomous learning examination systems, software platforms, etc. Purchasing sources are group purchasing and autonomous payment. Above digital resources with many types and sources are single library digital resource collection evaluation objects. Rational quantitative sequencing of evaluation objects is the basis of digital resource purchasing decision.
In order to guarantee compatibility of evaluation objects with many types and sources, the single library digital resource evaluation content shall include following aspects:

1) Academic, authoritative and applicable feature of content;

2) Organize and revealing level of digital resources;

3) User using guarantee capability;

4) Resource utilization performance.

Besides, evaluation shall be conducted according to the following principles:

1) System principle. Selection of evaluation indexes can correctly reflect the internal characteristics and essential properties of evaluation objects. All indexes shall be correlative, hierarchical and rationale in weight.

2) Quantification principle. Qualitative and quantitative evaluation shall be rationally used and effectively integrated.

3) Feasibility principle, including universal applicability of index system and availability of data.

4) Continuity principle. Evaluation index and method shall keep certain stability and shall be adjusted, improved and optimized through continuous evaluation experiment..

\section{Evaluation InDEX SyStEM AND METHOdOLOGY}

Based on above mentioned content and principle of university library digital resource evaluation and comprehensive reference of NISO Z39.7-200Xlibrary metering standard[2] formulated by National Information Standards Organization, COUNTER online network electronic resource usage statistics[3], SUSHI protocol [4] and Guideline of Metering Digital Resources of University Libraries [5] jointly issued by University Library and Information Guidance Committee of Ministry of Education and CALIS Management Center, mainly to support purchasing decision for construction of single library digital resources, the author designs the following evaluation index system, as shown in table I .

The research is sponsored by the " Research on the Evaluation of Multi source and Multi - type Resources of University Library in Digital Environment" project of Wuhan Education Science "13th Five-year Plan" (Project No. 2017C168). 
TABLE I. DIGITAL RESOURCE EVALUATION INDEX SYSTEM OF UNIVERSITY LIBRARY

\begin{tabular}{|c|c|c|c|c|c|c|c|c|c|c|c|c|c|c|}
\hline $\begin{array}{l}\text { Level I index } \\
\text { (weight) }\end{array}$ & \multicolumn{6}{|c|}{ A Content of electronic literature $(0.3)$} & \multicolumn{8}{|c|}{ B Retrieval system and function $(0.1)$} \\
\hline $\begin{array}{l}\text { Level II index } \\
\text { (weight) }\end{array}$ & \multicolumn{2}{|c|}{$\begin{array}{l}\text { A1 Matching degree } \\
\text { with important } \\
\text { subjects of this } \\
\text { library }(0.5)\end{array}$} & \multicolumn{2}{|c|}{$\begin{array}{c}\text { A2 Applicable object } \\
\text { of electronic literature } \\
(0.3)\end{array}$} & A3 Dat & ource $(0.2)$ & \multicolumn{2}{|c|}{$\begin{array}{c}\text { B1 } \\
\text { Retrieval } \\
\text { function } \\
(0.4)\end{array}$} & \multicolumn{3}{|c|}{$\begin{array}{l}\text { B2 Retrieval } \\
\text { result }(0.2)\end{array}$} & \multicolumn{2}{|c|}{$\begin{array}{l}\text { B3 Retrieval } \\
\text { interface }(0.2)\end{array}$} & $\begin{array}{l}\text { B4 User } \\
\text { service } \\
(0.2)\end{array}$ \\
\hline $\begin{array}{l}\text { Level I index } \\
\text { (weight) }\end{array}$ & \multicolumn{4}{|c|}{ C Access performance $(0.1)$} & \multicolumn{10}{|c|}{ D Supplier service $(0.1)$} \\
\hline $\begin{array}{l}\text { Level II index } \\
\text { (weight) }\end{array}$ & $\begin{array}{l}\mathrm{C} 1 \\
\text { Access } \\
\text { mode } \\
(0.25)\end{array}$ & $\begin{array}{c}\text { C2 } \\
\text { Access } \\
\text { speed } \\
(0.25)\end{array}$ & $\begin{array}{c}\mathrm{C} 3 \\
\text { Percent } \\
\text { age of } \\
\text { access } \\
\text { failures } \\
(0.25)\end{array}$ & $\begin{array}{l}\text { C4 off } \\
\text { campus } \\
\text { access } \\
\text { restriction } \\
(0.25)\end{array}$ & $\begin{array}{l}\text { D1 Usage } \\
\text { statistics } \\
\text { report } \\
(0.2)\end{array}$ & \multicolumn{2}{|c|}{$\begin{array}{l}\text { D2 Providing } \\
\text { access authority of } \\
\text { management } \\
\text { system }(0.2)\end{array}$} & D3 D & pdi & & $\begin{array}{c}\text { D4 } \\
\text { Training } \\
(0.3)\end{array}$ & \multicolumn{2}{|r|}{$\begin{array}{l}\text { D5 } \\
\text { Treatment } \\
\text { of illegal } \\
\text { use }(0.1)\end{array}$} & $\begin{array}{c}\text { D6 } \\
\text { Function } \\
\text { improveme } \\
\text { nt }(0.1)\end{array}$ \\
\hline $\begin{array}{l}\text { Level I index } \\
\text { (weight) }\end{array}$ & \multicolumn{4}{|c|}{ E Usage of electronic literature (0.1) } & \multicolumn{8}{|c|}{ F Price factors of electronic literature $(0.2)$} & \multicolumn{2}{|c|}{$\begin{array}{c}\text { G Saving of } \\
\text { electronic } \\
\text { literature }(0.1)\end{array}$} \\
\hline $\begin{array}{l}\text { Level II index } \\
\text { (weight) }\end{array}$ & \multicolumn{2}{|c|}{$\begin{array}{l}\text { E1 User feedback } \\
\qquad(0.6)\end{array}$} & $\begin{array}{l}\text { E2 Free } \\
\text { trial } \\
(0.2)\end{array}$ & $\begin{array}{c}\text { E3 Usage } \\
\text { statistics } \\
(0.2)\end{array}$ & $\begin{array}{c}\mathrm{F} 1 \\
\text { Discount } \\
\text { margin } \\
(0.3)\end{array}$ & $\begin{array}{l}\text { F2 Annual } \\
\text { rise }(0.3)\end{array}$ & & $\begin{array}{r}3 \text { Grou } \\
\text { sidy or } \\
(0.2)\end{array}$ & & \multicolumn{3}{|c|}{$\begin{array}{l}\text { F4 School or college } \\
\text { subsidy }(0.2)\end{array}$} & & \\
\hline
\end{tabular}

Above index system has A-G 7 level I indexes and 24 level II indexes, and comprehensively applies multiple index comprehensive evaluation method[6], analytic hierarchy process (AHP) [7], Delphi method[8] and sampling survey method. In order to make the resource evaluation of university libraries have wider participatory, try to quantize the subjective opinions of user group and organically integrate the objective statistic data, the author designs the questionnaire form. See table II for details.
Different indexes correspond to different evaluation subjects. For example, the price factors of electronic literature in level I index $\mathrm{F}$ involve historic price of data resource, increase amount and subsidies. The price is assigned by acquisition librarian of university library; as for $\mathrm{C} 4$ off campus access restriction and E1 user feedback in level II indexes, sampling investigation can be conducted to university users via the simple questionnaire in table II.

TABLE II. QUESTIONNAIRE OF DIGITAL RESOURCE EVALUATION OF UNIVERSITY LIBRARY

\begin{tabular}{|c|c|c|c|}
\hline \multirow{3}{*}{ Electronic resource name } & \multicolumn{3}{|c|}{ Points } \\
\hline & 100 & 50 & 0 \\
\hline & Yes & General & No \\
\hline A1 Whether the content matches with relevant subject? & & & \\
\hline A2 Whether it adapts to all students and teachers in this college (department)? & & & \\
\hline A3 Whether the data source is authoritative and academic? & & & \\
\hline $\begin{array}{l}\text { B1 Whether the retrieval function is complete? (logical grouping / relative retrieval/secondary retrieval/ } \\
\text { category retrieval) }\end{array}$ & & & \\
\hline $\begin{array}{l}\begin{array}{l}\text { B2 Whether the retrieval result has analysis } \\
\text { degree/author/periodical/year/subject) }\end{array}\end{array}$ & & & \\
\hline B3 Whether the retrieval interface is friendly? & & & \\
\hline B4 Whether it can provide personalized services and user assistance? & & & \\
\hline C2 Whether the access speed is high? & & & \\
\hline C3 Whether the electronic resource can be successfully accessed each time in the campus? & & & \\
\hline C4 Whether the electronic resource can be accessed off the campus? & & & \\
\hline E1 Whether you recommend library to purchase this electronic resource? & & & \\
\hline
\end{tabular}

\section{EVALUATION AlgORITHM AND ASSIGNMENT RULES}

The evaluation result of university library digital resources via above two level weight index system is shown in different types in percentage system digit. Its algorithm formula is:
Score of level I indexes $=\sum$ score of level II index selected $\times$ corresponding level II index weight coefficient

Total score of electronic literature $=\sum$ score of level $I$ index selected $\times$ corresponding level I index weight coefficient.

Assignment rules of single index are as follows: 
- A1 Matching degree with important subjects of this library (0.5): if the proportion of relevant important subjects selected by the library to all subjects of the library is $\geq 80 \%$, it is 100 points; 10 points are reduced for each decrement of $10 \%$;

- A2 Applicable object of electronic literature (0.3): if it is applicable to all readers, it is 100 points. Otherwise, the points shall be reduced with the reduction of application object range;

- A3 Data source (0.2): if the data is from authorities, presses with strong academic performance or professional societies, it is 100 points. Otherwise, the points are reduced with the weakening of authority, academy and specialty;

- B1 Retrieval function (0.4): if all following functions are met, it is 100 points. 20 points will be reduced for decrement of one function: a) retrieval field is complete; b) logical grouping; c) related retrieval (extended retrieval or synonym retrieval); $d$ ) secondary retrieval; e) classified retrieval;

- B2 Retrieval result (0.2): if all functions are possessed, it is 100 points; 20 points are reduced if 1 function is less; a) Analysis function of retrieval result (based on time/ correlation degree/author/periodical/year/subject); b) complete downloading mode (email/printing/saving/online browsing); c) good quality of downloaded literatures (clear and readable / no missed part); d) direct introduction of retrieval result in bibliographic management system (such as EndNote and NoteFirst); e) library OPAC system linkage function;

- B3 Retrieval interface (0.2): if all functions are possessed, it is 100 points; 50 points are reduced if 1 function is less; a) friendly retrieval interface and $b$ ) retrieval platform integrated with other resources to realize the trans-library retrieval in one platform;

- B4 User service (0.2): if all following functions are possessed, it is 100 points; 50 points are reduced if 1 function is less; a) provide user help; b) provide personalized service;

- C1 Access mode (0.25): if there is special access line or there is mirror site in China, it is 100 points. If it is required that the library sets mirror or the international flow fee shall be paid, it is 60 points. As for standalone version, it is 0 point.

- C2 Access speed (0.25): the point is determined according to access speed of different databases. It is 100 points if the access speed is very fast;

- C3 Percentage of access failures (0.25): the point is determined according to frequency of database access failures measured by different modes. It is 100 points if there is no access failure.

- C4 Off campus access restriction (0.25): if the off campus access function is provided or the library is allowed to provide the off campus access function, it is 100 points. It is 0 point if the function isn't provided or the library is restricted.

- D1 Usage statistics report (0.2): if the conforming usage statistics report is provided quarterly, it is 100 points. If the usage statistics report submitted is nonconforming, it is 60 points; if the usage statistics report isn't submitted, it is 0 point;

- D2 Providing access authority of management system (0.2): if the access authority of management system of library is provided, it is 100 points. Otherwise, it is o point.

- D3 Data update (0.1): if the data is updated in a timely manner according to regulation of protocol, it is 100 points. As for each $10 \%$ increment of update lagging (lagging days/specified update cycle), 10 points are reduced.

- $\quad$ D4 Training (0.3): if the training and relevant training materials are provided in a timely manner according to user's demand and the required effect is achieved, it is 100 points. If the training and relevant training materials are provided, but not in a timely manner or the effect is general, it is 60 points. If the training and relevant training materials are provided, but the required effect isn't achieved, it is 40 points. In case of failure to provide, it is 0 point.

- D5 Treatment of illegal use (0.1): if the user illegal use is reasonably solved, it is 100 points. Otherwise, it is 0 point.

- D6 Function improvement (0.1): if all functions and services are improved immediately based on demand suggestions and problem feedback of users, it is 100 points. If functions and services are improved, but the effect isn't obvious, it is 60 points. If functions and services aren't improved, it is 0 point;

- $\quad$ E1 User feedback (0.6): if VIP users (more than three users) or general users (more than five users) hold that it is necessary database, it is 100 points. If there is no feedback, it is 60 points. If users hold that it is useless, it is 0 point.

- $\quad$ E2 Free trial (0.2): if the free trail for enough time is provided (more than 3 months), it is 100 points. If free trail is provided, but the time isn't enough, it is 60 points. If free trail isn't provided, it is 0 point;

- $\quad$ E3 Trial statistics (0.2): if the trial statistics is in front rank of similar databases which are trialed by the library or in front rank of national/group similar colleges, it is 100 points. If the rank is declined, the point reduces.

- $\quad$ F1 Discount margin (0.3): full score is 100 points; 10 points are reduced for each $10 \%$ decrement of discount margin. 
- F2 Annual rise (0.3): if the annual rise is $\leq 5 \%$, it is 100 points; 10 points are reduced for each $1 \%$ increment.

- $\quad$ F3 Group subsidy or share (0.2): if the group issues subsidies or all literatures purchased from the group can be shared, it is 100 points. If share isn't available and subsidy isn't issued, it is 0 point.

- F4 school or college subsidy (0.2): if the subsidy is $50 \%$ of price or higher, it is 100 points. 25 points are reduced for each $10 \%$ decrement;

- G Saving of electronic literature (0.1): if the electronic literature can be saved or permanently used, it is 100 points. Otherwise, it is 0 point.

\section{CONCLUSIONS}

University library digital resource evaluation index system and method mentioned in this paper start from business flow of university library resource construction, and comprehensively apply many evaluation methods to abstract and quantize the multi-source and multi-type evaluation objects and complex attributes. The evaluation object group has wide coverage. The assignment rules are specific, have practical operability and the possibility of widespread promotion and can provide reference for purchasing decision of digital resources. According to prediction of British Library, in $2020,75 \%$ periodicals in the world are only published in digital form or mixed form of digit and paper version[9]. Therefore, university library digital resource construction and evaluation objects will be distributed wider and the forms will become richer. As for whether this evaluation index system can meet relevant business development of university library, the system shall be revised, improved and expanded in further research and repeated experiments.

\section{ACKNOWLEDGMENT}

In this paper, the research is sponsored by the "Research on the Evaluation of Multi - source and Multi - type Resources of University Library in Digital Environment" project of Wuhan Education Science "13th Five-year Plan" (Project No. 2017C168).

\section{REFERENCES}

[1] Wang Jingjing, Zhu Benjun and Xiao Long. Library in an Evolving Academic Environment: New Strategy and Direction in Collection Development -Conference Review of "the 3rd Sino-American Academic Library Forum for Cooperation and Development", Journal of Academic Libraries. 2016(05):5-11(In Chinese)

[2] Liu Wei and Wang Changyu. Comparison of ISO2789, NISOZ39.7 and E-METRICS digital resource evaluation standards. Journal of Library Science, 2010, 32(8):102-105(In Chinese)

[3] COUNTER .https://www.projectcounter.org/

[4] SUSHI. http://www.niso.org/workrooms/sushi

[5] Guideline of Metering Digital Resources of University Libraries (revised in 2007). [2007-10-6]. http://www.scal.edu.cn/(In Chinese)

[6] Qiu Dong. Multiple Index Comprehensive Evaluation Method. Statistical Research, 1990, 7(6):43-51(In Chinese)

[7] Gao Qijiao, Yan Fengbin and Chi Bin. Application of Analytic Hierarchy Process (AHP) in Data Quality Evaluation. Information Technology, 2011(3):168-169(In Chinese)

[8] Xu Aiting. Application and Difficulty of Delphi Method. China Statistics, 2006(9):57-59(In Chinese)

[9] British library 2020 vision.

http://www.bl.uk/aboutus/stratpolprog/2020vision/2020A3.pdf 